\title{
O PROCESSO DE REFORMULAÇÃO CURRICULAR DO ENSINO TÉCNICO INTEGRADO AO ENSINO MÉDIO NO IFSULDEMINAS - CAMPUS MUZAMBINHO
}

\author{
EL PROCESO REFORMULACIÓN CURRICULAR DE LA EDUCACIÓN TÉCNICA \\ INTEGRADA CON LA ESCUELA SECUNDARIA EN IFSULDEMINAS - CAMPUS \\ MUZAMBINHO
}

\begin{abstract}
THE CURRICULAR REFORMULATION OF TECHNICAL EDUCATION INTEGRATED WITH HIGH SCHOOL IN IFSULDEMINAS - CAMPUS MUZAMBINHO
\end{abstract}

\author{
Renato Aparecido DE SOUZA ${ }^{1}$ \\ Aracele Garcia de Oliveira FASSBINDER ${ }^{2}$ \\ Carolina José MARIA ${ }^{3}$
}

RESUMO: O texto objetiva descrever a reformulação dos Projetos Pedagógicos dos Cursos (PPCs) técnicos integrados ao ensino médio do IFSULDEMINAS - Campus Muzambinho. Trata-se de um relato de experiência, na perspectiva do gestor escolar, durante o primeiro semestre do ano de 2019. Cerca de 100 professores foram envolvidos neste processo. A reformulação foi estruturada em: (i) criação de Grupos de Trabalho (GTs); (ii) estabelecimento do perfil do egresso; e (iii) Construção das diretrizes curriculares com a definição dos conhecimentos necessários para atingir o perfil de formação. Como desfecho houve duas dimensões: (i) Perfil do egresso reestruturado e (ii) reestruturação da carga horária em sua totalidade. O processo de reformulação curricular foi finalizado com a construção de instrumentos normativos baseados sobretudo nas demandas de inovação e empreendedorismo, estabelecendo coerência com itinerário formativo, dando sequencialidade nas etapas formativas e ultrapassando a visão curricular como conjuntos isolados de conhecimentos e práticas desarticuladas.

PALAVRAS-CHAVE: Ensino técnico profissionalizante. Metodologias ativas. Aprendizagem centrada no estudante.

RESUMEN: El texto tiene como objetivo describir la reformulación de Proyectos Pedagógicos (PPC) del Curso Técnico integrados a la escuela secundaria de IFSULDEMINAS - Campus Muzambinho. Este es un informe de experiencia, desde la

\footnotetext{
${ }^{1}$ Instituto Federal de Educação, Ciência e Tecnologia do Sul de Minas Gerais (IFSULDEMINAS), Muzambinho - MG - Brasil. Diretor-Geral do Campus Muzambinho. Doutorado em Engenharia Biomédica (UNIVAP). ORCID: https://orcid.org/0000-0003-0125-411X. E-mail: renato.souza@ifsuldeminas.edu.br

${ }^{2}$ Instituto Federal de Educação, Ciência e Tecnologia do Sul de Minas Gerais (IFSULDEMINAS), Muzambinho - MG - Brasil. Diretora de Desenvolvimento Educacional do Campus Muzambinho. Doutorado em Ciências da Computação e Matemática Computacional (USP). ORCID: https://orcid.org/0000-0003-2670-3823. E-mail: aracele.garcia@muz.ifsuldeminas.edu.br

${ }^{3}$ Universidade Metodista de Piracicaba (UNIMEP), Piracicaba - SP - Brasil. Docente do Programa de PósGraduação em Educação. Doutorado em Educação (UNIMEP). ORCID: https://orcid.org/0000-0003-0249-2670. E-mail: caroljosemaria@gmail.com
}

RIAEE - Revista Ibero-Americana de Estudos em Educação, Araraquara, v. 16, n. 4, p. 2791-2807, out./dez. 2021. e-ISSN: 1982-5587 DOI: https://doi.org/10.21723/riaee.v16i4.13634 
perspectiva del gerente de la escuela, durante el primer semestre de 2019. Alrededor de 100 maestros participaron en este proceso. La reformulación se estructuró en: (i) creación de Grupos de Trabajo (GT); (ii) establecer el perfil del graduado; y (iii) Construcción de pautas curriculares con la definición del conocimiento necesario para lograr el perfil de capacitación. Como resultado, habia dos dimensiones: (i) Perfil del graduado reestructurado y (ii) reestructuración de la carga de trabajo total. El proceso de reformulación curricular finalizó con la construcción de instrumentos normativos basados principalmente en las demandas de innovación y emprendimiento, estableciendo coherencia con el itinerario formativo, dando secuencia a las etapas formativas y yendo más allá de la visión curricular como conjuntos aislados de conocimiento y prácticas desarticuladas.

PALABRAS CLAVE: Educación técnica profesional. Metodologías activas. Aprendizaje centrado en el alumno.

ABSTRACT: The text aims to describe the reformulation of the Technical Course Pedagogical Projects (PPCs) integrated to the high school of IFSULDEMINAS - Campus Muzambinho. This is an experience report, from the perspective of the school manager, during the first semester of 2019. About 100 teachers were involved in this process. The reformulation was structured in: (i) creation of Working Groups (WGs); (ii) establishing the graduate profile; and (iii) Construction of curricular guidelines with the definition of the knowledge necessary to achieve the training profile. As an outcome, there were two dimensions: (i) Profile of the restructured graduate and (ii) restructuring of the total workload. The curriculum reformulation process ended with the construction of normative instruments based mainly on the demands of innovation and entrepreneurship, establishing coherence with the formative itinerary, giving sequence to the formative stages, and going beyond the curricular vision as isolated sets of knowledge and disjointed practices.

KEYWORDS: Professional technical education. Active methodologies. Student-centered learning.

\section{Introdução}

Um desafio vem absorvendo a realidade dos cursos de educação profissional técnica de forma articulada ao ensino médio nos Institutos Federais de Educação, Ciência e Tecnologia: a necessidade de reformulação Projetos Pedagógicos dos Cursos (PPCs), com a finalidade de efetivamente aplicar estratégias inovadoras de ensino e aprendizagem que contemplem o currículo integrado na prática, o qual implica articulação entre conhecimentos básicos e técnicos, vislumbrando a formação humana integral dos estudantes.

Alinhado com essa política nacional, o Instituto Federal de Educação, Ciência e Tecnologia do Sul de Minas Gerais - IFSULDEMINAS, planejou elaborar, até o fim de 2019, uma Matriz de Referência Institucional para a organização dos projetos pedagógicos dos seus cursos técnicos integrados, por curso e por campus, adotando como referência de carga 
horária dos cursos técnicos integrados às estabelecidas na Resolução CNE/CEB nº. 06/2012, ou Resolução do CNE que venha a substitui-la, de 3.000, 3.100 ou 3.200 horas, conforme o número de horas para as respectivas habilitações profisssionais do Catálogo Nacional de Cursos Técnicos, excluída a carga horária do Estágio Supervisionado Obrigatório e atividades complementares, quando previsto (IFSULDEMINAS, 2019).

O ensino técnico integrado ao ensino médio no Brasil possui uma vinculação histórica com o mundo do trabalho, seja pela possibilidade de se conseguir um emprego logo após concluída essa etapa de ensino, ou pela finalidade de ingresso no Ensino Superior (com enfoque na preparação para vestibulares e outros processos seletivos), em que a formação nesse nível está atrelada à inserção no mercado de trabalho (RAMOS, 2008). De fato, um currículo integrado organiza o conhecimento e desenvolve o processo de ensinoaprendizagem de forma que os conceitos sejam apreendidos como sistema de relações de uma totalidade concreta que se pretende explicar/compreender (COTRIM-GUIMARÃES; OUVERNEY-KING, 2018).

O processo de reestruturação de currículos apresenta novas perspectivas (e às vezes antigas, mas com uma roupagem atualizada), e revigora o ambiente de ensino e aprendizagem, promovendo trocas de conhecimentos e práticas (MALLINEN; PROKKI, 2016). Particularmente no IFSULDEMINAS - Campus Muzambinho, o processo de reestruturação dos PPCs tem sido estabelecido pela imersão de sua comunidade docente e de técnicos em assuntos educacionais no pensamento de reformulação de processos pedagógicos, adotando métodos centrados no estudante e de trabalho colaborativo (SOUZA; SILVA; COIMBRA, 2018).

Inserido nesse contexto, e considerando a necessidade conjuntural de reformulação dos cursos técnicos integrados ao ensino médio do IFSULDEMINAS - Campus Muzambinho, surge este estudo, o qual objetivou descrever a reformulação dos PPCs dos cursos técnicos em agropecuária, alimentos e informática, ambos integrados ao ensino médio, à luz de currículos inovadores, com metodologias centradas no estudante e na tentativa de melhor atender as demandas de aprendizagens do século XXI. Trata-se de um relato de experiência, na perspectiva do gestor escolar que direcionou e estruturou todos os processos de reformulação dos PPCs. Por fim, os resultados são apresentados estabelecendo um paralelo documental entre os currículos reformulados/antes e os idealizados/atuais. 


\section{Material e Métodos}

Trata-se de um relato de experiência desenvolvido durante o primeiro semestre do ano de 2019, no IFSULDEMINAS - Campus Muzambinho, que apresenta os processos e etapas de reformulação dos PPCs dos cursos técnicos integrados ao ensino médio: técnico em Agropecuária, Técnico em Alimentos e Técnico em Informática.

Toda a reestruturação curricular do IFSULDEMINAS - Campus Muzambinho se deu pautada por fundamentos norteadores, tais como: (a) relação e articulação entre a formação desenvolvida no ensino médio e a qualificação para o trabalho, na perspectiva da formação integral dos educandos por meio de atividades de ensino, pesquisa e extensão planejadas de acordo com o perfil do egresso do estudante; (b) trabalho assumido como princípio educativo, tendo sua integração com a ciência, a tecnologia e a cultura como base da proposta políticopedagógica e do desenvolvimento curricular; (c) articulação da Educação Básica com a Educação Profissional e Tecnológica, na perspectiva da integração entre saberes específicos para a produção do conhecimento e a intervenção social, assumindo a pesquisa e a extensão como princípios pedagógicos; (d) com foco na articulação e na formação humana integral; (e) inclusão de atividades didático pedagógicas que articulem e garantam a curricularização do ensino, da pesquisa e da extensão; (f) realização de práticas profissionais que possibilitem ao estudante o contato com o mundo do trabalho e assegurem a formação teórico-prática intrínseca ao perfil de formação técnica; (g) criação de uma organização curricular orgânica que privilegie a articulação e a interdisciplinaridade entre os componentes curriculares e as metodologias integradoras, com vistas à promoção da formação ética, política, entre outras, tratando-as como fundamentais para a formação integral dos estudantes; (h) previsão de carga horária específica para Prática Profissional Integrada (PPI), a ser desenvolvida ao longo do curso, a fim de promover o contato real e/ou simulado com a prática profissional pretendida pela habilitação específica (IFSULDEMINAS, 2019).

A reformulação foi estruturada em três passos metodológicos: (i) criação de Grupos de Trabalho (GTs) e compreensão da legislação vigente; (ii) estabelecimento do perfil do egresso; e (iii) Construção das diretrizes curriculares com a definição dos conhecimentos necessários para atingir o perfil de formação. Como desfecho houve duas dimensões: (i) Perfil do egresso reestruturado levando em consideração sobretudo as demandas de inovação e empreendedorismo, estabelecendo coerência com itinerário formativo, dando sequencialidade nas etapas formativas e ultrapassando a visão curricular como conjuntos isolados de conhecimentos e práticas desarticuladas; e (ii) Reestruturação da carga horária na sua 
totalidade, tanto do núcleo básico como núcleo técnico, bem como do número de vagas ofertadas no vestibular.

Para tanto, adotou-se a metodologia de integração dos conjuntos teórico-práticos dos Núcleos Pedagógicos envolvidos no processo: Básico (NB), Núcleo Tecnológico (NT) e Núcleo Politécnico (NPoli). O processo metodológico fundamentou-se àquele relatado pela equipe pedagógica do Instituto Federal Farroupilha (SILVA; ROSA, 2013).

O primeiro passo foi a formalização da criação de Grupos de Trabalho (GTs) (Quadro 1) com suas respectivas competências que trabalharam no processo de estudo dos fundamentos e da legislação vigente, adotando-se sobretudo a Lei $n^{\circ} 11.892$, de 29 de dezembro de 2008, que instituiu a Rede Federal de Educação Profissional, Científica e Tecnológica, cria os Institutos Federais de Educação, Ciência e Tecnologia, e dá outras providências; e o parecer CNE/CEB No: 11/2012, que deu origem à Resolução $\mathrm{CNE} / \mathrm{CEB}$ 06/2012, que normatiza a educação profissional e os cursos técnicos. Cerca de 100 profissionais foram envolvidos na reformulação dos PPCs dos três cursos, incluindo professores e técnicos administrativos em educação do Campus Muzambinho.

Quadro 1 - Grupos de Trabalho para elaboração dos projetos pedagógicos

\begin{tabular}{|c|c|}
\hline Grupos de Trabalho & Composição \\
\hline $\begin{array}{l}\text { Comitê assessor do } \\
\text { ensino }\end{array}$ & $\begin{array}{l}\text { Diretores de Desenvolvimento Educacional de todos os campi do IFSULDEMINAS; Membros da } \\
\text { Pró-Reitoria de Ensino; Pedagogos; Coordenadores de cursos. }\end{array}$ \\
\hline $\begin{array}{l}\text { Comissão de Gestão } \\
\text { do Campus } \\
\text { Muzambinho }\end{array}$ & $\begin{array}{l}\text { Diretoria de Desenvolvimento Educacional; Coordenadoria-Geral de Ensino; Pedagoga; Setor de } \\
\text { Orientação Educacional. }\end{array}$ \\
\hline Núcleo Técnico (NT) & $\begin{array}{l}\text { Professores da área técnica dos cursos Técnicos Integrados ao Ensino Médio. } \\
\text { Composto por } 3 \text { grupos: GT Área Técnica Informática, GT Área Técnica Agropecuária, GT Área } \\
\text { Técnica Alimentos. }\end{array}$ \\
\hline Núcleo Básico (NB) & $\begin{array}{l}\text { Professores do Ensino Médio, divididos em subgrupos, em alguns momentos, tais como: a) } \\
\text { Ciências Humanas e suas Tecnologias: História, Geografia, Filosofia e Sociologia. b) Ciências da } \\
\text { Natureza e suas Tecnologias: Química, Física e Biologia. c) Linguagens, Códigos e suas } \\
\text { Tecnologias: Língua Portuguesa, Literatura, Língua Estrangeira (Inglês ou Espanhol), Artes, } \\
\text { Educação Física. d) Matemática e suas Tecnologias: Matemática. }\end{array}$ \\
\hline $\begin{array}{l}\text { Núcleo Politécnico } \\
\text { (NPoli) }\end{array}$ & $\begin{array}{l}\text { Integração dos membros do Núcleo Institucional de Pesquisa e Extensão (NIPE), Escritório Local } \\
\text { de Inovação (ELITT), Clube de Empreendedorismo, Empresas Júniores, a fim de garantir o } \\
\text { trabalho como princípio educativo, a pesquisa e a extensão curricularizadas e como princípio } \\
\text { pedagógico. }\end{array}$ \\
\hline
\end{tabular}

RIAEE - Revista Ibero-Americana de Estudos em Educação, Araraquara, v. 16, n. 4, p. 2791-2807, out./dez. 2021. e-ISSN: 1982-5587 DOI: https://doi.org/10.21723/riaee.v16i4.13634 


\begin{tabular}{|l|l|}
\hline \multirow{2}{*}{$\begin{array}{l}\text { Temas Transversais e } \\
\text { Educacão Inclusiva }\end{array}$} & $\begin{array}{l}\text { Integração de membros do Núcleo de Apoio às Pessoas Portadoras de Necessidades Específicas } \\
\text { (NAPNE), Núcleo de Estudos e Pesquisa em Gênero, Educação e Sexualidade (NEGES), Núcleo } \\
\text { Animais (CEUA), Centro de Estudos Ambientais (CEAM). Para dar conta da formação integral, } \\
\text { além da formação humana e política, os currículos buscam, também, o reconhecimento das } \\
\text { identidades de gênero e étnico-raciais. Essa formação se efetiva através de ações articuladas com } \\
\text { os Núcleos Inclusivos que atuam no campus. }\end{array}$ \\
\hline Normativa Docente & $\begin{array}{l}\text { Propostas para a Normativa Docente. } \\
\text { Integração da Comissão de Acompanhamento da Normativa Docente e GT’s dos cursos, com o } \\
\text { objetivo de valorizar e dar peso às atividades fins: ensino, pesquisa e extensão. }\end{array}$ \\
\hline EaD & $\begin{array}{l}\text { Profissionais ligados ao Ensino a Distância. Verificação de possibilidades ligadas ao Ensino a } \\
\text { Distância na matriz curricular. } \\
\text { Recursos e apoio necessário: capacitação, organização curricular, leis relacionadas. }\end{array}$ \\
\hline
\end{tabular}

Fonte: Elaborado pelos autores

Em seguida, passou-se à compreensão do perfil de formação dos egressos do curso, a qual foi definida a partir do Estudo do Catálogo Nacional dos Cursos Técnicos (CNCT) e, quando necessário, complementado com o Código Brasileiro de Ocupações (CBO). Com intuito de favorecer e fomentar a compreensão da aprendizagem centrada no estudante no processo de reestruturação dos PPCs, a gestão do campus promoveu uma capacitação denominada "Formação para o ensino profissional: Interdisciplinaridade e Integração Curricular". Os instrutores dessa capacitação, além de possuírem capacitação pedagógica na Finlândia, atuaram em diversos outros Institutos Federais que já passaram pelo processo de reestruturação de PPCs dos cursos técnicos integrados ao ensino médio.

A capacitação contou com dois encontros e os principais tópicos abordados foram: metodologias ativas, integração curricular, curricularização da pesquisa e da extensão, adequação da carga-horária curricular, perfil do egresso e ferramentas digitais.

Metodologias ativas de aprendizagem analógicas também foram utilizadas no processo de reestruturação, uma vez que com elas foi possível contemplar momentos e ambientes em que a tecnologia não é viável. De maneira destacada, o desenvolvimento do perfil do egresso dos cursos Agropecuária, Alimentos e Informática utilizando o mapa da empatia; uma atividade colaborativa denominada Think, Pair, Share; e a prática do Jogo "T.E.A.C.H. project". Neste jogo elaborado pelos próprios responsáveis pela oficina, utilizando cartas especificamente criadas para este fim, os participantes deveriam criar conexões entre conceitos e práticas docentes, algumas delas até então desconhecidas por alguns e, 
desenvolveu-se estratégias de desenvolvimento do currículo apoiadas nas cartas previamente escolhidas. Esta ferramenta permitiu criar o debate entre os professores, apresentar conceitos e práticas pedagógicas, estimular o compartilhamento de experiências exitosas e promover a inovação no planejamento curricular.

Além da discussão entre pares nos GTs, uma pesquisa online foi conduzida com alunos, egressos e empresas, a fim de coletar dados que pudessem ajudar os GTs a atualizarem o perfil do egresso.

Considerado o perfil do egresso, na sequência foram conduzidos os trabalhos para a construção das diretrizes curriculares com a definição dos conhecimentos necessários para atingir o perfil de formação. Esta organização curricular é de fundamental importância e é o que faz com que o currículo integrado se diferencie de uma organização clássica, na medida em que os conhecimentos são articulados de forma integrada e em sequência para dar conta da formação pretendida. Essa forma de organização, no entanto, faz com que cursos diferentes não tenham, por exemplo, a mesma organização curricular ou a mesma sequência de conteúdo na área básica. Por fim, além da organização e articulação curricular horizontal entre as disciplinas, foi necessário, ainda, definir estratégias para que a integração vertical e com integração de atividades como a extensão ocorressem ao longo do curso.

Dessa maneira, diversos encontros ocorreram com os professores do GT-NT, a fim de refinarem os conteúdos para o "Núcleo Tecnológico". Conteúdos não selecionados para a ênfase tecnológica passaram a compor o "Núcleo Politécnico". Em paralelo, o GT-NB também se reuniu para organizar as disciplinas e o ementário do "Núcleo Básico".

Um dos momentos cruciais desse processo de reestruturação dos PPCs foram os encontros de integração entre os docentes da área básica e os docentes da área técnica. Os docentes da área básica foram divididos em subgrupos: Linguagens, Códigos e suas Tecnologias (Arte, Educação Física, Línguas); Ciências Humanas e suas Tecnologias (Filosofia/Sociologia/Geografia/História); Ciências da Natureza, Matemática e suas Tecnologias (Biologia, Física, Matemática, Química). Cada subgrupo se encontrou com os docentes da área técnica dos cursos de informática, alimentos e agropecuária, apresentando o conteúdo trabalhado. Os docentes das áreas técnicas também descreveram os conteúdos e as habilidades técnicas que são abordadas. Nesses encontros foi possível identificar conteúdo sombreado, possibilidades de integração e a adequação do momento de trabalhar certos conteúdos.

Para a construção das diretrizes curriculares, foi realizada uma oficina de curricularização da extensão, que permitiu aos docentes identificarem atividades didático- 
pedagógicas que articulem de forma efetiva o ensino, a pesquisa e, principalmente, a extensão, de forma regulamentada dentro do currículo. Isso significou incorporar atividades de extensão aos PPCs. Para isso, utilizou-se a estratégia think-pair-share. Inicialmente, foram apresentados casos de sucesso conduzidos em outros institutos federais. Após uma reflexão individual, os professores se reuniram em grupos e salas diferentes, a fim de preencherem um canvas específico, descrevendo qual atividade de extensão poderia ser incorporada à matriz do curso. Em seguida, os representantes de cada grupo ou curso socializaram as ideias que tiveram (Fig. 1).

Figura 1 - Profissionais de educação envolvidos em oficina acerca da curricularização de extensão

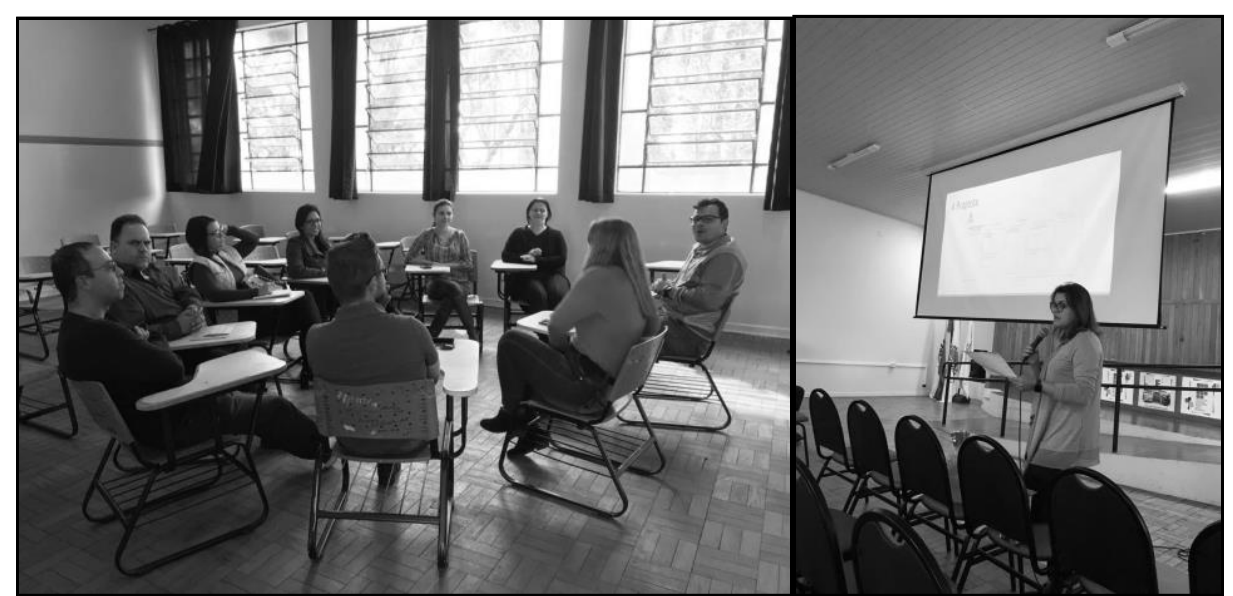

Fonte: Acervo dos autores

Os currículos reformulados com base nos passos acima indicados passaram a ser trabalhados nas turmas do IFSULDEMINAS - Campus Muzambinho no ano de 2020.

\section{Resultados e Discussão}

Tem sido descrito que o Ensino Médio no Brasil é o nível de ensino cujos debates acerca do currículo são mais controversos, sendo esse fator considerado o grande nó do sistema educacional brasileiro (VIEIRA et al., 2020). Dessa maneira, o Ensino Médio tem sofrido contínuas reformas curriculares apoiadas em princípios norteadores, concepção de currículo, organização curricular e sistemas de avaliação pedagogicamente diversificados, além de flexibilidade do percurso formativo (SILVEIRA; SILVA, 2018).

No presente estudo, os resultados das alterações aprovadas são apresentados levando em consideração duas dimensões que indicaram as principais alterações obtidas com a 
reformulação dos PPCs dos cursos técnicos em agropecuária, alimentos e informática, ambos integrados ao ensino médio.

Dimensão 1: Perfil do egresso reestruturado levando em consideração sobretudo as demandas de inovação e empreendedorismo, estabelecendo coerência com itinerário formativo, dando sequencialidade nas etapas formativas e ultrapassando a visão curricular como conjuntos isolados de conhecimentos e práticas desarticuladas. Sendo assim, foram obtidos os seguintes perfis profissionais:

(a) Técnico em Agropecuária Integrado ao Ensino Médio: Atuar de forma empreendedora, inovadora e inclusiva acompanhando a evolução da profissão; Ter habilidades de comunicação e de trabalho em equipes multidisciplinares, adotando um enfoque holístico e integrador na construção de novas estratégias de uso múltiplo dos recursos naturais que são necessárias ao incremento profissional, que lhe permitirá a interpretação e compreensão de fatos sociais (históricos, geográficos, culturais e econômicos) e a intervenção sobre a realidade; Domina o saber-fazer, o saber-ser, o saber-saber e o saber-conviver; Valorizar e respeitar as variações linguísticas, compreendendo-as na dimensão históricocultural, como marca de identidade dos sujeitos e como objeto que possibilita a interação dos indivíduos nas organizações; Dominar a habilidade de raciocínio lógico e complexo necessários para a proposição e resolução de problemas cotidianos; Possuir visão humanística crítica e consistente sobre o impacto de sua atuação profissional na sociedade como disseminador e facilitador do conhecimento, permitindo uma abordagem sistêmica capaz de privilegiar a busca pela sustentabilidade como forma de promover a segurança alimentar, a geração de renda e a conservação do meio ambiente; Conjugar habilidades e competências que permitem planejamento, execução, acompanhamento, comercialização, orientação e fiscalização de todas as fases dos empreendimentos agropecuários, na produção animal, vegetal, práticas de engenharia rural e agroindustrial; e Atuar na administração de empresas rurais, em programas de assistência técnica, extensão rural, pesquisa e associativismo.

(b) Técnico em Alimentos Integrado ao Ensino Médio: Ser capaz de analisar as características econômicas, sociais e ambientais da área para propor e implementar as atividades específicas de forma sustentável; Ter visão empreendedora e de gestão empresarial, integrando os conhecimentos adquiridos; interagindo e aprimorando continuamente seus aprendizados a partir da convivência democrática com culturas, modos de ser e pontos de vista divergentes; Compreender processos industriais nas áreas de beneficiamento, processamento e conservação de alimentos, atuando no controle de qualidade destes produtos e de suas matérias primas; Implantar a execução e acompanhamento dos programas de 
higienização e qualidade visando a segurança alimentar, monitorando o controle de qualidade dos alimentos por meio de manuseio técnico e preciso dos instrumentos e equipamentos para realizações de análises físico-químicas, microbiológicas e sensoriais; Participar nas áreas de pesquisas, extensão e inovação, no desenvolvimento de novos produtos e marketing; Prestar assistência técnica em indústrias de alimentos, instituições, órgãos de fiscalização, cooperativas, serviços de alimentação e outros; Elaborar no âmbito de suas atribuições legais, laudos, perícias, pareceres e relatório; e Apoiar ações nutricionais baseadas na segurança alimentar e nos conceitos de alimentação adequada e subjetiva.

(c) Técnico em Informática Integrado ao Ensino Médio: Ter desenvolvido um conjunto de competências científicas, profissionais e humanísticas capaz de atender às atuais demandas da sociedade, o que, contudo, não significa reproduzir mecanicamente valores e posturas; Ser um indivíduo com postura crítica, responsável, ética e científica, respeitando as diferenças e o meio ambiente, possuindo visão holística e crítica, e da realidade social, cultural, econômica e ambiental do meio onde está inserido, sendo capaz de contribuir como um agente transformador seja no mundo do trabalho, na família ou na vida em sociedade. Atuar para o desenvolvimento e manutenção de processos sustentáveis e contribuir para a construção de uma sociedade mais justa; Assumir um perfil de trabalho em equipe, sendo capaz de lidar com contextos caracterizados por mudanças, competitividade, necessidade permanente de inovação, revendo posições e práticas; e ser capaz de contribuir para o desenvolvimento regional, seja por meio da constituição de negócio próprio, com possibilidades de geração de emprego e renda para a população do entorno, ou no desenvolvimento de ações empreendedoras como colaborador em organizações de terceiros.

Dimensão 2: Reestruturação da carga horária na sua totalidade, tanto do núcleo básico como núcleo técnico, bem como do número de vagas ofertadas no vestibular (Tabela 1).

Tabela 1 - Reestruturação da carga horária e número de vagas dos cursos técnicos do Campus Muzambinho

\begin{tabular}{|c|c|c|c|}
\hline & Agropecuária & Alimentos & Informática \\
\hline \multirow[t]{3}{*}{ Vagas } & Antes: 120 & Antes: 30 & Antes: 60 \\
\hline & Atual: 140 & Atual: 35 & Atual: 90 \\
\hline & Diferença: +20 & Diferença: +5 & Diferença: +30 \\
\hline \multirow[t]{3}{*}{ NB } & Antes: $2530 \mathrm{~h}$ & Antes: $1320 \mathrm{~h}$ & Antes: $1246 \mathrm{~h} 40 \mathrm{~min}$ \\
\hline & Atual: $1980 \mathrm{~h}$ & Atual: $1833 \mathrm{~h} 14 \mathrm{~min}$ & Atual:1943h20min \\
\hline & Diferença: $-550 \mathrm{~h}$ & Diferença:+513h14min & Diferença: $+697 \mathrm{~h} 40 \mathrm{~min}$ \\
\hline \multirow[t]{3}{*}{ NT } & Antes: $1723 \mathrm{~h} 20 \mathrm{~min}$ & Antes: $2493 \mathrm{~h}$ & Antes: $2497 \mathrm{~h} 20 \mathrm{~min}$ \\
\hline & Atual: $1356 \mathrm{~h} 40 \mathrm{~min}$ & Atual: $953 \mathrm{~h} 18 \mathrm{~min}$ & Atual: $1136 \mathrm{~h} 40 \mathrm{~min}$ \\
\hline & Diferença: -366h40min & Diferença: $-1539 \mathrm{~h} 42 \mathrm{~min}$ & Diferença: - 1360h40min \\
\hline \multirow[t]{3}{*}{ NPoli } & Antes: $0 \mathrm{~h}$ & Antes: 0h & Antes: $0 \mathrm{~h}$ \\
\hline & Atual: $100 \mathrm{~h}$ & Atual: $476 \mathrm{~h} 38 \mathrm{~min}$ & Atual: $73 \mathrm{~h} 20 \mathrm{~min}$ \\
\hline & Diferença: $+100 \mathrm{~h}$ & Diferença: $+476 \mathrm{~h} 38 \mathrm{~min}$ & Diferença: + 73h20min \\
\hline
\end{tabular}




\begin{tabular}{llll} 
Total & Antes: $4253 \mathrm{~h} 20 \mathrm{~min}$ & Antes: $3813 \mathrm{~h}$ & Antes: $3860 \mathrm{~h}$ \\
& Atual: $3436 \mathrm{~h} 40 \mathrm{~min}$ & Atual: $3426 \mathrm{~h} 40 \mathrm{~min}$ & Atual: $3273 \mathrm{~h} 20 \mathrm{~min}$ \\
& Diferença: $-816 \mathrm{~h} 40 \mathrm{~min}$ & Diferença: $-386 \mathrm{~h} 20 \mathrm{~min}$ & Diferença: $-586 \mathrm{~h} 40 \mathrm{~min}$ \\
\hline
\end{tabular}

Fonte: Elaborado pelos autores

Por meio da reestruturação da carga horária foi permitido ao menos 4 inovações pedagógicas:

(a) A curricularização da extensão: Por meio de práticas de campo; visitas aos laboratórios e execuções de ensaios; Visitas técnicas a empresas e feiras da área; Interpretação e discussão de textos técnicos; Apresentação de vídeos técnicos; Apresentação de seminários; Desenvolvimento de pesquisa com aplicações concretas na sociedade; Participação de projetos de extensão que se baseiam em bases tecnológicas descritas neste plano de curso; Trabalhos em equipe; Relatórios de ensaios e atividades desenvolvidas em aula ou atividade extra-aula; Participação em um Projeto Integrador durante as três séries do curso, que desenvolva e articule as competências e habilidades trabalhadas durante toda a formação; Realização de avaliações interdisciplinares; Participação em projetos culturais, de recreação, esporte e lazer.

(b) A aplicação de fato de um projeto integrador: ao reestruturar o currículo, vários debates nos levaram a evitar a sobreposição de conteúdos e, até mesmo, de disciplinas. Importante mudança foi alimentada como realocar as disciplinas nos períodos propostos dos cursos para que as disciplinas servissem aos cursos integrados e não mais a atividades pouco integradoras existentes.

(c) Espaço na distribuição das aulas durante a semana: com a redução da carga horária os educandos poderão participar dos projetos integradores, projetos de pesquisa e extensão, projetos de qualidade de vida, entre outros. Um dos dilemas clássicos dos cursos técnicos integrados era a carga pesada (número de aulas/semana e quantidade de disciplinas): com a redução da carga horária e das sobreposições de conteúdos/disciplinas aponta-se com a nova distribuição para uma realidade bastante distinta. Espera-se pelo menos 2 períodos semanais (manhã ou tarde) para que as atividades listadas acima possam fazer parte do cotidiano dos alunos. Os projetos em questão poderão ser realizados de forma inter ou multidisciplinar, ou mesmo contemplar todas as disciplinas. Dentro destes projetos nasce a aplicação ou mesmo aprofundamento dos conteúdos trabalhados em sala de aula.

(d) Maior espaço para organização, capacitação e reciclagem dos docentes: a expectativa é que haja por parte dos docentes um maior aproveitamento dos períodos sem aula 
(dada à redução) para encontros semanais de ajustes e debates pedagógicos que envolvam os referidos cursos. Além de aplicação de projetos de ensino e aprofundamento dos conteúdos.

Vários são os desafios da educação brasileira neste século. Neste trabalho, a ênfase foi na reestruturação de projetos pedagógicos em cursos com duração de três anos e aproximadamente 4000 horas letivas que deveriam ser condensados em torno de 3200 horas, proporcionando um ambiente mais salutar para todos os atores do processo de ensino e aprendizagem.

A redução não implicou apenas em um corte de disciplinas ou supressão de conteúdos. A redução foi acompanhada com qualidade nos processos de apropriação do conhecimento e este talvez tenha sido o grande desafio, mas que pode ser amenizado por meio de estratégias como o ensino significativo por meio da aprendizagem baseada em projetos e problemas ou ainda uma ação trans ou interdisciplinar. Acima de tudo, as propostas de redução foram acompanhadas de soluções integradoras e significativas para o ensino, já que apesar da necessidade de redução na carga horária, havia também que se pensar na necessidade de combinação entre as disciplinas para promover o ensino significativo.

O currículo do projeto pedagógico do curso não foi apenas 'enxugado', nessa perspectiva ele é revitalizado. Importante também salientar que com as ações de formação o currículo pôde ser construído com os atores que o colocarão em prática, permitindo maior apropriação das ações a serem tomadas, transformando-o em peça "viva" e orgânica e não documento de bancada a ser consultado eventualmente.

Além disso, tais ações de transformação do ambiente educacional também promovem a colaboratividade entre os atores do conhecimento e auxiliam na formação de uma Comunidade Profissional de Aprendizagem. DuFour et al. (2005) destacam que essa comunidade desenvolve os meios para (i) promover mudança significativa no ambiente escolar; (ii) oferecer a união e participação entre/na comunidade escolar; (iii) produzir aprendizagem significativa e para a vida toda, dentre outros elementos. Todavia, a aplicação de tal estratégia deve vir acompanhada de uma formação continuada que proporcione o mínimo de conhecimentos para que os professores possam, de forma colaborativa, iniciarem a escalada para o topo da cooperatividade educacional. Formações continuadas permeadas por ações que são "mão na massa" são espaços disseminadores de reflexão, discussão e promoção de segurança na execução do trabalho em grupo, já que muitas vezes os profissionais não dispõem de um momento em que possam se conhecer e a oficina oportuniza a comunicação coletiva, o que fomenta uma futura colaboratividade na aplicação de novas metodologias. 
A manutenção da qualidade das ofertas até então feitas pelo IFSULDEMINAS Campus Muzambinho deverá ser garantida com a conscientização dos alunos da importância dos estudos integrados (sem valorização exacerbada de um núcleo ou outro); e dada a realidade regional, para evitar a queda da demanda em razão das expectativas dos nossos estudantes (muitos procuraram a instituição para o sucesso nas provas do ENEM), é necessário viabilizar caminhos para suprimir as perdas sofridas pelo núcleo básico (onde a redução acabou mais profunda) e conscientizar os docentes que o projeto é integrador e, portanto, o trabalho de todos valoriza o de cada um.

Consideramos que o processo de reformulação deva ser um trabalho em permanente ajuste. A melhoria contínua reflete os desafios enfrentados principalmente no tocante à atuação em disciplinas integradoras, tais como exigência de tempo maior de planejamento das aulas, dificuldade dos alunos na compreensão da interdisciplinaridade, uma vez que estão acostumados com aulas no estilo "tradicional", bem como dificuldade dos professores para o trabalho cooperativo. Por outro lado, as transformações e avanços em andamento destacam evidências do trabalho em equipe, dinamicidade das aulas, ricas trocas de experiências entre os professores nos momentos de aula, aprendizagem significativa, diálogo e inovação pedagógica.

Dessa maneira, descrevemos alguns relatos de professores atores nesta experiência de reformulação curricular:

(i) "No novo PPCs dos cursos técnicos integrados tivemos a proposta de criar e implementar uma disciplina integradora entre Educação Física e Artes, ambas fazem parte da área de linguagem, essa proximidade favorece no momento de pontuarmos as competências gerais e as habilidades que são recomendadas na BNCC. Entretanto é um desafio, pois os professores têm que aprender a trabalhar de forma cooperativa, os objetivos e as atividades devem ser planejados para atender as duas disciplinas, e devemos ter a preocupação com a interdisciplinaridade, ou seja, um diálogo constante entre os professores, para que nenhuma disciplina ofusque a outra".

(ii) "Apesar de tratarmos a interdisciplinaridade como tema urgente no campo das atualizações ou revisões pedagógicas, ainda há muita resistência em colocá-la em prática. A falta de experiência nesse tipo de metodologia e a falta de parâmetros contribuem para um certo receio na adoção dessa prática. No mundo escolar, daquilo que sei e vivi, há poucas instituições interessadas e empenhadas em adotar a interdisciplinaridade de forma abrangente. Nesse aspecto, o IFSULDEMINAS - Campus Muzambinho se distingue ao incorporar a prática da interdisciplinaridade como modelo de ação pedagógica de forma oficial (e oficializada) em unidades curriculares. Sinto-me privilegiada por ter tido a oportunidade de participar dessa implementação, um desejo antigo meu, e que até então não havia sido possivel colocar em prática".

(iii) "Repensar o plano de curso de forma interdisciplinar foi um desafio em vários sentidos. Primeiro porque quando partimos para graduação,

RIAEE - Revista Ibero-Americana de Estudos em Educação, Araraquara, v. 16, n. 4, p. 2791-2807, out./dez. 2021. e-ISSN: 1982-5587 
mestrado e doutorado, ficamos especialistas em um assunto, e meio que "deixamos de lado" os demais - sem nem perceber que estão todos ligados. Ai começamos a carreira docente e, novamente, focamos somente naquele contexto das disciplinas que lecionamos. Num primeiro momento, achei que seria somente conversar com os professores do ensino básico que lecionavam disciplinas que eu usava nas aulas do técnico, mas durante o percurso é que percebi que seria muito mais que isso! Tivemos que repensar todo o conteúdo ministrado, em função do perfil profissional que gostaríamos de formar, e associar ao conteúdo obrigatório exigido no ensino médio. Foi um desafio e tanto! Depois de muitas discussões, explicações e exaustivas reuniões, chegamos num documento que reflete nossa vontade de fazer a interdisciplinaridade dar certo. Dentro desse contexto, as disciplinas de Projeto Integrador geraram muitas dúvidas entre nós. Como fazer com que o aluno utilize várias áreas do conhecimento ao mesmo tempo num só projeto? A única forma que entendemos fazer isso possivel foi colocando TODOS os docentes do curso nessa empreitada. Tanto professores do ensino médio quanto professores do ensino técnico, são hoje orientadores e co-orientadores de projetos de pesquisa, extensão e ensino - todos na área do curso. E eles são escolhidos pelos próprios alunos, em função da curiosidade com a área e afinidade com o professor. Acreditamos que, assim, esse projeto que visa integrar as diversas áreas de conhecimento obtenha êxito, e estamos colhendo os frutos dessa ideia inovadora através do entusiasmo e ideias brilhantes que os próprios alunos nos trazem".

Por fim, deve-se destacar que todos os processos aqui descritos estão disponíveis em uma plataforma digital com todos os produtos da reestruturação curricular criada: https://sites.google.com/muz.ifsuldeminas.edu.br/integracao.. Além disso, as reformulações dos currículos foram aprovadas no Conselho Superior (CONSUP) do IFSULDEMINAS, sendo publicadas em 18 de dezembro de 2019 as resoluções CONSUP 121/2019, 122/2019 e 123/2019, as quais dispõem respectivamente sobre a alteração dos Projetos Pedagógicos de Cursos (PPCs) dos cursos Técnico em Agropecuária Integrado ao Ensino Médio, Técnico em Alimentos Integrado ao Ensino Médio e Técnico em Informática Integrado ao Ensino Médio IFSULDEMINAS do Campus Muzambinho.

\section{Considerações finais}

Diante do atual cenário, onde o Ensino Técnico integrado ao Ensino Médio tem ocupado o centro de debates nacionais a partir de demandas evocadas pela Rede Federal de Educação Tecnológica, torna-se latente a necessidade de discussões acerca de experiências que promoveram, ao longo da história, ensaios de modernização da educação cujos resultados mostram-se promissores e que levaram a cabo o ideal de promoção de uma educação de qualidade e integradora. Nessa direção, o presente trabalho representou um esforço inicial de 
aproximação de estudos acerca de experiências de ensino que, em diferentes tempos e espaços, realizaram ensaios inovadores.

O processo de reformulação curricular do ensino técnico integrado ao ensino médio do IFSULDEMINAS - Campus Muzambinho foi finalizado com a participação da comunidade pedagógica, que construiu estes instrumentos normativos baseada sobretudo nas demandas de inovação e empreendedorismo, estabelecendo coerência com o itinerário formativo, dando sequencialidade nas etapas formativas e ultrapassando a visão curricular como conjuntos isolados de conhecimentos e práticas desarticuladas. Fundamentalmente, ao menos 4 inovações pedagógicas foram inseridas nos PPCs reformulados: curricularização da extensão, aplicação de fato de um projeto integrador, espaço para melhor distribuição das aulas durante a semana e maior espaço para organização, capacitação e reciclagem dos docentes.

Ensaios como os aqui apresentados são exemplos férteis de projetos de ensino que se ocuparam do conjunto de elementos necessários para a promoção da formação integral do estudante, incluindo uma efetiva compreensão do termo "Educação Integral”.

AGRADECIMENTOS: Agradecemos toda a comunidade docente e técnicos administrativos do IFSULDEMINAS - Campus Muzambinho que contribuíram direta e indiretamente com a conclusão deste trabalho.

\section{REFERÊNCIAS}

COTRIM-GUIMARÃES, I. M. A.; OUVERNEY-KING, J. R. Por dentro do sistema educacional Finlandês: elementos para se repensar o ensino médio integrado no Brasil. In: SEMINÁRIO NACIONAL DO ENSINO MÉDIO INTEGRADO, 2., 2018. Anais [...] Brasília: Instituto Federal de Brasília. p.55-70. Disponível em: https://www.even3.com.br/anais/snemi/55101-por-dentro-do-sistema-educacional-finlandeselementos-para-se-repensar-o-ensino-medio-integrado-no-brasil/. Acesso em: 29 mar. 2020.

DUFOUR, R. et al. Recurring Themes of Professional Learning Communities and the Assumptions They Challenge. In: On Common Ground: The Power of Professional Learning Communities. Bloomington: Solution Tree Press., 2005. p. 7-30.

Instituto Federal de Educação, Ciência e Tecnologia do Sul de Minas Gerais [IFSULDEMINAS]. 2019. Resolução do Conselho Superior (CONSUP) n. 021 de 27 de março de 2019. Dispõe sobre a aprovação das Diretrizes Indutoras do IFSULDEMINAS para a oferta de cursos técnicos integrados ao Ensino Médio. Disponível em: https://portal.ifsuldeminas.edu.br/images/PDFs/Conselho_Superior_/resolucoes/2019/21.pdf. Acesso em: 20 maio 2019. 
MALLINEN, S.; PROKKI C. "Eu não sou um professor, sou um Educador": Finnish education meets Brazilian creativity. Tampere: Kirjapaino Hermes Ou, 2016. 117 p.

RAMOS, M. Concepção do ensino médio integrado. Universidade do Estado do Rio de Janeiro (UERJ), Rio de Janeiro, RJ, Brasil. 2008. Disponível em:

https://tecnicadmiwj.files.wordpress.com/2008/09/texto-concepcao-do-ensino-mediointegrado-marise-ramos1.pdf. Acesso em: 15 maio 2019.

SILVA, E.G.B.; ROSA, D.Z. O ensino médio integrado no Instituto Federal Farroupilha: fundamentos, metodologia de constituição. In: SEMINÁRIO NACIONAL DO ENSINO MÉDIO INTEGRADO, 2., 2018. Anais [...] Brasília: Instituto Federal de Brasília, 2018. p. 2-27. Disponível em: https://www.even3.com.br/anais/snemi/103240-o-ensino-mediointegrado-no-instituto-federal-farroupilha - fundamentos-metodologia-de-constituicao/. Acesso em: 29 mar. 2020.

SILVEIRA, E. L. D.; SILVA, R. R. D. A flexibilização como um imperativo político nas políticas curriculares para o Ensino Médio no Brasil: uma leitura crítica. Revista IberoAmericana de Estudos em Educação, Araraquara, v. 13, n. 4, p. 1759-1778, 2018. Disponível em: https://periodicos.fclar.unesp.br/iberoamericana/article/view/11226/7690. Acesso em: 01 fev. 2021.

SOUZA, R. A.; SILVA, G. C.; COIMBRA, M. B. B. Construção colaborativa para a educação inclusiva: como a experiência educacional finlandesa pode rechear esse processo? Revista Ibero-Americana de Estudos em Educação, Araraquara, v. 13, n. esp. 1, p. 576585, 2018. Disponível em:

https://periodicos.fclar.unesp.br/iberoamericana/article/view/11457/7336. Acesso em: 20 mar. 2020 .

VIEIRA, L. et al. Inovação curricular no ensino médio: das experiências exitosas às duvidosas propostas de mudança. Revista Ibero-Americana de Estudos em Educação, Araraquara, v. 15, n. 3, p. 1422-1442, 2020. Disponível em:

https://periodicos.fclar.unesp.br/iberoamericana/article/view/12720/9201. Acesso em: 03 fev. 2021. 


\section{Como referenciar este artigo}

SOUZA, R. A.; FASSBINDER, A. G. O.; MARIA, C. J. O processo de reformulação curricular do ensino técnico integrado ao ensino médio no IFSULDEMINAS - Campus Muzambinho. Revista Ibero-Americana de Estudos em Educação, Araraquara, v. 16, n. 4, p. 2791-2807, out./dez. 2021. e-ISSN: 1982-5587. DOI: https://doi.org/10.21723/riaee.v16i4.13634

Submetido em: 01/08/2021

Revisões requeridas em: 25/09/2021

Aprovado em: 01/10/2021

Publicado em: 21/10/2021 